\title{
How Does Dynamic Soil Permeability Affect the Soil response in a Nearly Saturated Porous Seabed?
}

\author{
Jeng DS ${ }^{1,2, *}$, Wu $S^{2}$ and Sun $\mathrm{K}^{3,4}$ \\ ${ }^{1}$ Southwest Jiaotong University, China \\ ${ }^{2}$ School of Engineering and Built Environment Griffith University, Australia \\ ${ }^{3}$ Hohai University, China \\ ${ }^{4}$ University of Bradford, $U K$ \\ *Corresponding author: Jeng DS, School of Engineering and Built Environment, Griffith University, Australia

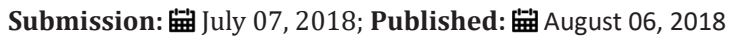

\begin{abstract}
Soil permeability is one of key factors in the prediction of the wave-induced seabed response, which will directly affect the design of foundation around marine installations. Most previous studies in the field treated the soil permeability as a constant, although it depends on numerous soil parameters. In this study, the soil permeability is considered as a function of pore water pressure, i.e., it varies in both spatial and time domains, as reported in the literature. With this new feature, the governing equation will become non-linear differential equations. Numerical examples demonstrate the significant influence of dynamic soil permeability on the wave-induced pore pressure and effective stresses.
\end{abstract}

Keywords: Dynamic permeability; Pore-water pressures; Soil response; Wave loading

\section{Introduction}

In the past a few decades, considerable efforts have been devoted to the phenomenon of the wave-soil interactions. One of the major reasons is that the evaluation of the wave-induced soil response and its resultant seabed instability is particularly important for coastal geotechnical engineers involved in the design of foundation of the offshore installations [1,2]. Another reason is that the poro-elastic theories for wave-soil interaction have been applied to field measurements such as determination of the shear modulus of seabed and the directional spectra of ocean waves, as well as acoustic waves propagating through porous media. Based on Biot's poro-elastic theory [3], several classic investigations for the wave-induced soil response have been carried out since the 1970s. Among these [4] proposed closed-form analytical solutions for the wave-induced oscillatory soil response in an isotropic, poro-elastic and infinite seabed. This model was further extended to three-dimensional cases by Hsu \& Jeng [5] for various soil conditions. Another different approximation, so-called boundary layer approximation, was proposed by Mei \& Foda [6], which provided simple formulations of the wave-induced soil response. This approximation can provide precise prediction of soil response in fine sand rather than coarse sand [7]. A detailed review of previous relevant research can be found by Jeng [8].

All the aforementioned studies have treated the soil permeability as a constant in the entire soil layer. In fact, soil permeability has been reported to be a function of void ratio $(e)$. Furthermore, pore-water pressure has been reported to bean other factor that affects to the soil permeability [9-11]. According to [4], the hydraulic conductivity was expressed as

$$
K(p)=\left\{\begin{array}{l}
K_{S}|p| \leq|\psi \alpha \varepsilon| \\
K_{S} e^{\alpha \psi \alpha \varepsilon} e^{\alpha p}|p|>|\psi \alpha \varepsilon|
\end{array}\right\}
$$

Table 1: Coefficient of permeability at full saturation $(K s)$, air-entry value $\psi_{\alpha \varepsilon}$ and desaturation coefficient (a) for some soils [5-7].

\begin{tabular}{|c|c|c|c|}
\hline Soil type & $K_{s}(\mathbf{m} / \mathbf{s})$ & \multirow{2}{*}{$(K p a)$} & $\alpha\left(\mathbf{k P a}^{-1}\right)$ \\
\hline Clay & $\begin{array}{r}10^{-10} \\
-10^{-8}\end{array}$ & $20-39$ & 0.016 for Beit Netofa clay \\
\hline Silt & $10^{-10-10^{-6}}$ & $7-155$ & 0.043 for a silt loam \\
\hline Sand & $10^{-5}-10^{-3}$ & $1-3$ & 0.106 for a fine sand \\
\hline Gravel & $10^{-2}-10^{-1}$ & Nil & 0.081 for Hpgiene sandstone \\
\hline
\end{tabular}


Where $\mathrm{K}_{\mathrm{s}}$ is coefficient of permeability at full saturation; $\alpha$ is desaturation coefficient and $\Psi_{\alpha \varepsilon}$ is air-entry value. For a fully saturated soil, $\alpha$ is set as zero. The values of these parameters for several soil types are listed in the following Table 1.

\section{Theoretical Formulations}

In this paper, a new model for the wave-induced soil response in porous seabed with dynamic soil permeability will be established. Based on the new model, a parametric study will be conducted to examine the effects of dynamic soil permeability on the waveinduced soil response in a porous seabed [12].

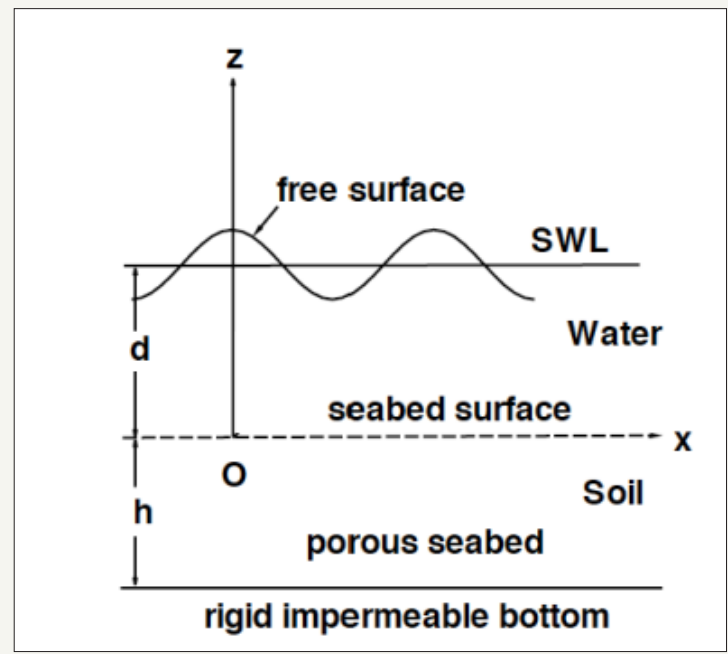

Figure 1: Sketch of the wave-seabed interactions.

Considering a soil matrix with a finite thickness (h) in a sandy seabed under wave loading as depicted in Figure 1. The wave crests are assumed to propagate in the positive $x$-direction, while the $z$-direction is positive upward from the water-soil interface (termed as the seabed surface) for the problem of wave-soil interaction.

\section{Linear wave theory}

For 2D progressive wave, the linear wave theory $[13,14]$ has been widely adopted in the wave induced soil response studies. A brief introduction and some key relationship equations are provided in this section.

For the first order wave theory, the velocity potential $\phi$ can be expressed as

$$
\phi=\frac{g H}{2 \omega} \frac{\cosh k z}{\cosh k d} \sin (k x-\omega t)
$$

Where $\mathrm{H}$ denotes wave height; $\mathrm{g}, \mathrm{d}$ and $\mathrm{t}$ are the gravity acceleration, time and the water depth above the seabed surface, respectively; $\mathrm{k}$ is wave number $(=2 \pi / L$, where $L$ is wavelength); and $\omega$ the wave frequency $=2 \pi / T$, where $T$ is the wave period).

The free surface is simultaneously transformed trigonometrically, the surface elevation $\boldsymbol{\eta}$ is

$$
\eta=\frac{H}{2} \cos (k x-\omega t)
$$

Based on the linear wave theory (3), the wavelength $(L)$ can be determined by the wave dispersion relation, i.e.,

$$
L=\frac{g T^{2}}{2 \pi} \tanh k d
$$

The wave $\omega$ and wave number $\mathrm{k}$ frequency also satisfy the dispersion relation, i.e,

$$
\omega^{2}=g k \tanh k d
$$

Substituting (2) and (3) into the Bernoulli equation, the wave pressure $\mathrm{p}_{\mathrm{w}}$ at any point within the $2 \mathrm{D}$ wave propagation domain at any time can be expressed as

$$
p_{w}(x, z, t)=\frac{\gamma_{w} H}{2} \frac{\cosh k z}{\cosh k d} \cos (k x-\omega t)(6)
$$

Where $\gamma_{w}$ is the unit weigh of the pore-water?

\section{Poro-elastic seabed model}

Based on conservation of mass, Biot's consolidation model [1] has been commonly used as the governing equation for porous flow in a porous seabed, i.e.,

$$
\nabla .(K \nabla p)-\gamma_{w} \eta \beta \frac{\partial p}{\partial t}=\gamma_{w} \frac{\partial \varepsilon}{\partial t}
$$

Where $K$ is soil permeability; is oscillatory pore-water pressures; $\gamma_{w}$ denotes the unit weight of pore-water; $n$ is soil porosity; and $t$ is the time.

In (7), the volume strain $\varepsilon$ and compressibility of pore fluid $\beta$ are defined as

$$
\varepsilon=\frac{\partial v}{\partial x}+\frac{\partial w}{\partial z}, \text { and } \beta=\frac{1}{K_{W 0}}+\frac{1-S_{r}}{P_{a b s}},(8)
$$

Substituting the expression of dynamic soil permeability, (1), into (7), the modified storage equation can be expressed as

$$
K \nabla^{2} p+a k\left[\left(\frac{\partial p}{\partial x}\right)^{2}+\left(\frac{\partial p}{\partial z}\right)^{2}\right]-\gamma_{w} n \beta \frac{\partial p}{\partial t}=\gamma_{w} \frac{\partial \varepsilon}{\partial t} \text { (9) }
$$


Where $K$ is the water-pore pressure related dynamic soil permeability, $\alpha$ is the de-saturation coefficient. When considering constant soil permeability, the second term on the left-hand-side of (9) will vanish, then (9) will become the conventional consolidation equation with constant soil permeability (8). For the effective stress concept and Hooke's law, based on conservation of momentum, the force balance equilibrium within the soil can be expressed as,

$$
\begin{aligned}
& G \nabla^{2} u+\frac{G}{1-2 \mu} \frac{\partial \epsilon}{\partial x}=\frac{\partial p}{\partial x}(10) \\
& G \nabla^{2} w+\frac{G}{1-2 \mu} \frac{\partial \epsilon}{\partial z}=\frac{\partial p}{\partial z},(11)
\end{aligned}
$$

Where $G$ is shear modulus of soil, which is related to Poisson's ration $\mu$ and Young's modulus $(E)$, as $\mathrm{G}=E=2(1+\mu)$.

Under the plane strain conditions, the relationship between stresses and soil displacements can be expressed as,

$$
\begin{gathered}
\sigma_{x}^{\prime}=2 G\left(\frac{\partial u}{\partial x}+\frac{\mu}{1-2 \mu} \in\right) \\
\sigma_{z}^{\prime}=2 G\left(\frac{\partial w}{\partial z}+\frac{\mu}{1-2 \mu} \in\right) \\
\tau_{x z}=G\left(\frac{\partial u}{\partial z}+\frac{\partial w}{\partial x}\right)
\end{gathered}
$$

Where $\sigma_{x}^{\prime}$ and $\sigma_{z}^{\prime}$ are effective normal stresses in the $x$ - and $z$-directions, respectively; and $\tau_{\mathrm{xz}}$ is the shear stresses.

\section{Boundary conditions}

For a homogeneous soil matrix, the wave-induced soil response to the exciting wave can be obtained subject to some appropriate boundary conditions at the rigid impermeable bottom and at the seabed surface. Firstly, zero displacement are assumed for the soil resting on an impermeable rigid bottom at a finite depth $(h)$ below the water-soil interface, as shown in Figure 1, thus

$$
\mathrm{u}=\mathrm{w}=0 \text {, at } \mathrm{z}=-\mathrm{h}(15)
$$

And no vertical flow occurs across the horizontal boundary,

$$
\frac{\partial p}{\partial z}=0, \text { at } z=-h(16)
$$

Secondly, the vertical normal stress and shear stress vanish on the seabed surface, i.e.,

$$
\sigma_{z}^{\prime}=\tau_{x z}=0, \text { at } z=0
$$

Thirdly, the pore-water pressure on the upper soil boundary is defined to equal the wave pressure at the seabed surface $(z=0)$. Based on (6), the pore-water pressure at the top boundary can be expressed as

$$
p=p 0 \cos (k x-\omega t)=\frac{\gamma_{w} H}{2 \cosh k d} \cos (k x-\omega t), a t z=0,
$$

Where $p_{0}$ is the amplitude of dynamic wave pressures

Finally, to solve the boundary value problem numerically, the computational domain is set as 3 times of wavelength in the horizontal direction. At the lateral boundary conditions, impermeable boundary conditions are set in both sides. As reported in (15), such a computation also main is sufficient for the concerned region at the middle of the computational domain. The wave-induced pore pressures and soil displacement can be obtaining by solving the governing equations, ( 9 and 10,11), with above appropriate boundary conditions first. Then, the effective normal stresses and shear stress can be obtained from (12-14).

\section{Results and Discussion}

The new contribution of this paper is to consider the dynamic soil permeability in the existing models for wave-seabed interactions. In this section, some preliminary results will be presented and focus on the effects of dynamic soil permeability versus constant permeability. For the following numerical example, basic wave and soil properties in North Sea are listed in (Table 2). With the same wave parameters settings, numerical modelling has been conducted for two types of sandy seabed with varied permeability coefficients $\left(\mathrm{K}_{\mathrm{s}}\right)$ and the air-entry values $\Psi_{\alpha \varepsilon}$ generally speaking; sand particles (range in diameter from $0.0625 \mathrm{~mm}$ to $2 \mathrm{~mm}$ ) with smaller particle size and smaller void ratios may lead

\begin{tabular}{|c|c|}
\hline \multicolumn{2}{|c|}{ Wave Characteristics } \\
\hline Wave period $(\mathrm{T})[\mathrm{sec}]$ & 15 \\
\hline Water depth (d) [m] & 70 \\
\hline Wave height $(\mathrm{H})[\mathrm{m}]$ & 3 \\
\hline Wavelength (L) [m] & 311.59 \\
\hline density of water $\left(\rho_{w}\left[\mathrm{~kg} / \mathrm{m}^{3}\right]\right)$ & 1,030 \\
\hline \multicolumn{2}{|c|}{ Seabed Characteristics } \\
\hline Seabed thickness $(\mathrm{h})[\mathrm{m}]$ & 25 \\
\hline Porosity (n) [-] & 0.4 \\
\hline Poissons ratio $(\mu)[-]$ & 0.333 \\
\hline Shear modulus $(\mathrm{G})\left[\mathrm{N} / \mathrm{m}^{2}\right]$ & 107 \\
\hline Soil permeability (Ks) [m/sec] & $10^{-2}(\mathrm{CS})$ and $10^{-4}(\mathrm{FS})$ \\
\hline Degree of saturation $(\mathrm{Sr})[-]$ & 0.932 \\
\hline Parameter $\left[\psi_{\alpha \varepsilon} \mathrm{kPa}\right]$ & $1(\mathrm{CS})$ and $3(\mathrm{FS})$ \\
\hline $\operatorname{Parameter}(\alpha)[1 / \mathrm{kPa}]$ & 0.106 \\
\hline
\end{tabular}
to lower permeable seabed environment. For our purpose of study, without the rigid definition of coarse and fine sand, the seabed with larger $\mathrm{K}_{\mathrm{s}}\left(10^{-2} \mathrm{~m} / \mathrm{s}\right)$ and smaller $\Psi_{\alpha \varepsilon}$ assumed to be a coarse-sand (CS) seabed; while the smaller $\mathrm{K}_{\mathrm{s}}\left(10^{-4} \mathrm{~m} / \mathrm{s}\right)$ and larger $\Psi_{\alpha \varepsilon}(3 \mathrm{kPa})$ imply that the seabed is possibly formed with fine sand (FS). The rest of the seabed characteristics are assumed to be the same for both cases.

Table 2: Input data for numerical examples.

\section{$\mathrm{CS}=$ coarse sand; $\mathrm{FS}=$ fine sand}

Figure 2 illustrates the wave-induced pore-water pressures in both coarse-sand seabed and fine-sand seabed. In the figures, the results of the conventional models with constant soil permeability are also included as dashed lines, while the present models with dynamic soil permeability is presented in solid lines. Since the pore 
pressure varies with the time, the results are presented at different times intervals, $t=T=0,1 / 4,1 / 2,3 / 4$ and 1 . It can be found in Figure $2 \mathrm{a}$ that the difference between dynamic soil permeability and constant permeability is significant in coarse-sand seabed, compared with that in fine-sand seabed (Figure 2b). This implies that effects of dynamic soil permeability is more important in coarse sand (i.e., large soil permeability), because the dynamic pore pressure can be easier to transfer through coarse sand. It also observed from Figure 2 that dynamic soil permeability only affect the upper region of the seabed in fine sand.

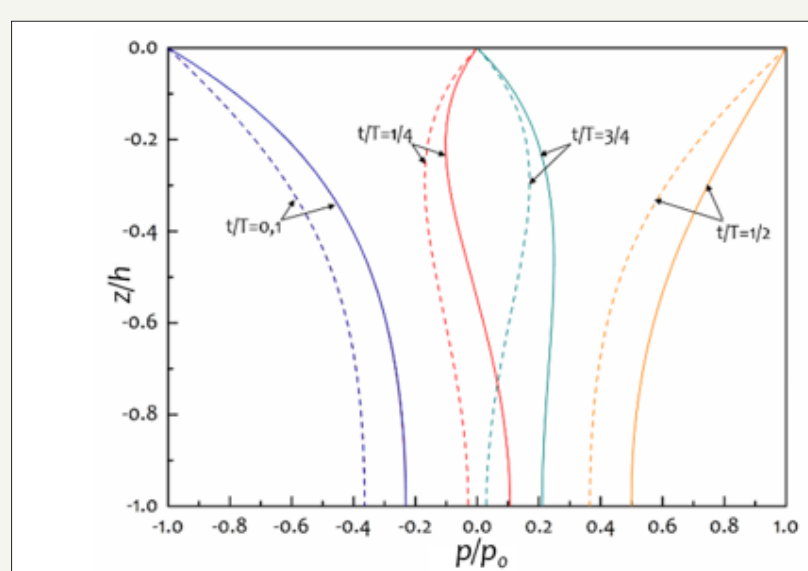

(a) Coarse-sand seabed

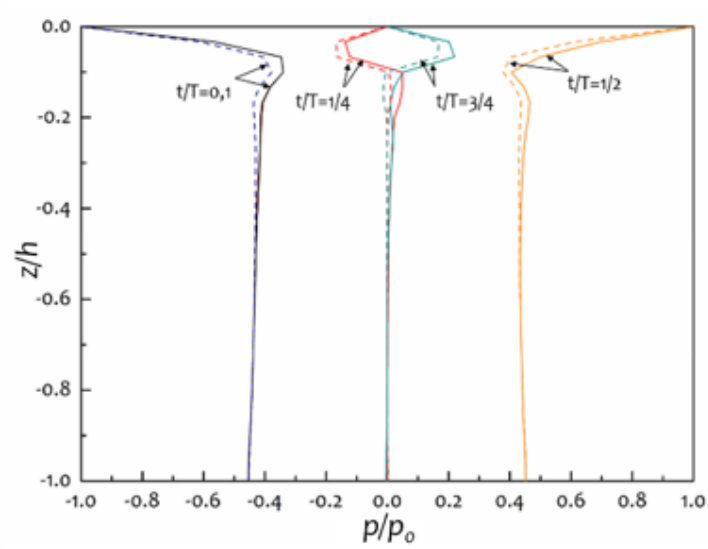

(b) Fine-sand seabed

Figure 2: Vertical distribution of wave-induced pore-water pressures versus soil depth for various time intervals in coarsesand seabed and fine-sand seabed at $\mathrm{x}=255 \mathrm{~m}$. Notation: solid lines=dynamic soil permeability; dashed lines $=$ constant soil permeability.

In addition to the wave-induced pore-water pressures, effective normal stress is another key factor in the prediction of the wave-induced seabed instability. Figure 3 presents the vertical distributions of the wave-induced vertical effective normal stresses in both coarse-sand seabed and fine-sand seabed. As shown in the figures, it is obvious that the effective stress with dynamic soil permeability is significantly different from that with constant permeability in both coarse-sand seabed and find sand. Compared Figure 3 with Figure 2, the effects of dynamic soil permeability on the vertical effective normal stresses are similar to that for porewater pressures.

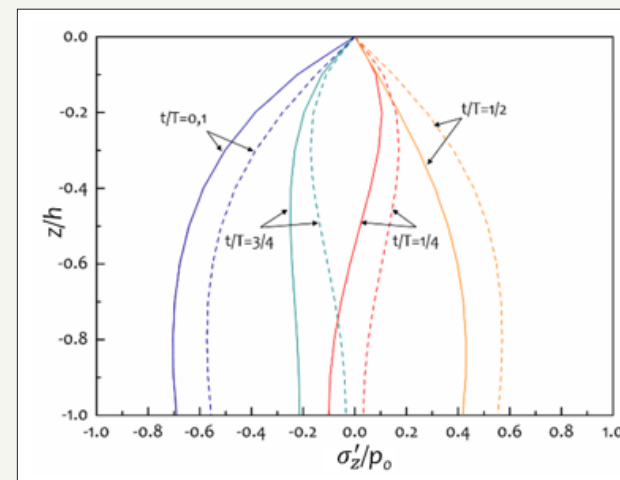

(a) Coarse-sand seabed

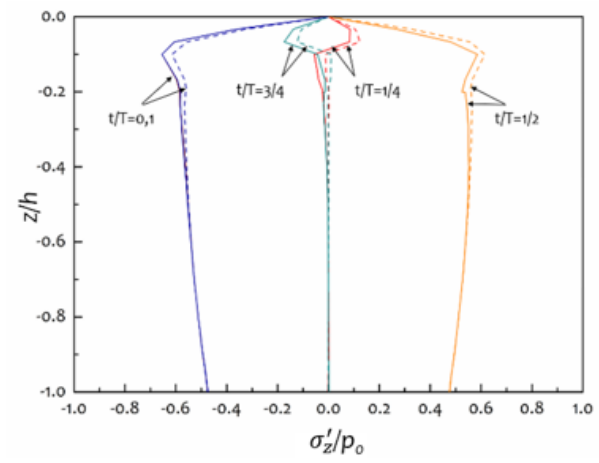

(b) Fine-sand seabed

Figure 3: Vertical distribution of wave-induced vertical effective normal stresses versus soil depth for various time interval in coarse-sand seabed and fine-sand seabed at $\mathrm{x}=255 \mathrm{~m}$. Notation: solid lines=dynamic soil permeability; dashed lines=constant soil permeability

\section{Conclusion}

In this paper, a new concept of dynamic soil permeability was introduced into the conventional model for the wave-seabed interactions. This is the first model considers the soil permeability as a function of pore-water pressures in the field of marine geo techniques in the literature. Based on the numerical examples presented in this paper, it is found that dynamic soil permeability has more significant influence on pore-water pressure both in coarse-sand seabed and in fine-sand seabed, compared with that on effective normal stress. Furthermore, influence of dynamic soil permeability on stress field in coarse-sand seabed occurs more remarkably in the lower layer of the seabed, whereas the dynamic 
soil permeability affects fine-sand response in the upper layer more intensively. In this paper, only preliminary results are presented to examine the effects of dynamic soil permeability. This new model can be further adopted to other engineering problems with marine installations such as breakwaters, pipelines, platforms and offshore wind turbine foundation ,etc., in the future.

\section{Acknowledgement}

The authors gratefully acknowledge the support of the Griffith University Research Service Team and the use of the High Performance Computing Cluster Gowanda to complete this research. The first author is thankful for the support of Royal Academy of Engineering Distinguish Visiting Fellowship Scheme to finalise this joint publication. The second author is thankful for the support of the Griffith University International Postgraduate Research Scholarship and the Griffith University Postgraduate Research Scholarship. The third author thanks for the support from Chinese Scholarship Council (CSC).

\section{References}

1. Jeng DS (2018) Mechanics of wave-seabed-structure interactions: modelling, processes and applications. Cambridge University Press, UK.

2. Sumer BM (2014) Liquefaction around marine structures. World Scientific, New Jersey, USA.

3. Biot MA (1941) General theory of three-dimensional consolidation. Journal of Applied Physics 12(2): 155-164.

4. Yamamoto T, Koning HL, Sellmeijer H, Hijum EV (1978) On the response of a poro elastic bed to water waves. Journal of Fluid Mechanics 87(1): 193-206.
5. Hsu JRC, Jeng DS (1994) Wave-induced soil response in an unsaturated an isotropic seabed of finite thickness. International Journal for Numerical and Analytical Methods in Geo mechanics 18(11): 785-807.

6. Mei CC, Foda MA (1981) Wave-induced response in a fluid-filled poroelastic solid with a free surface-a boundary layer theory. Geophysical Journal of the Royal Astronomical Society 66(3): 597-631.

7. Dean R, Dalrymple RA (1984) Water wave mechanics for engineers and scientists. World Scientific, Singapore.

8. Jeng DS (2003) Wave-induced sea floor dynamics. Applied Mechanics Reviews 56(4): 407-429.

9. Civan F, Rai CS, Sondergeld CH (2011) Shale-gas permeability and diffusivity inferred by improved formulation of relevant retention and transport mechanisms. Transport in Porous Media 86(3): 925-944

10. Gardner WR (1958) Some steady-state solutions of the unsaturated moisture flow equation with application to evaporation from a water table. Soil Science 85(4): 228-232.

11. Wu LZ, Zhang LM (2009) Analytical solution to 1d coupled water infiltration and deformation in unsaturated soils. International Journal for Numerical and Analytical Methodsin Geomechanics 33(6): 773-790.

12. Ye J, Jeng DS (2012) Response of seabed to natural loading-waves and currents. Journal of Engineering Mechanics 138(6): 601-613.

13. Hille D (1998) Environmental soil physics. Academic Press, New York, USA.

14. Van Genuchten MT (1980) A closed form equation for predicting the hydraulic conductivity of unsaturated soils. Soil Science Society of America Journal 44: 892-898.
Creative Commons Attribution 4.0 International License

For possible submissions Click Here

\section{Submit Article}

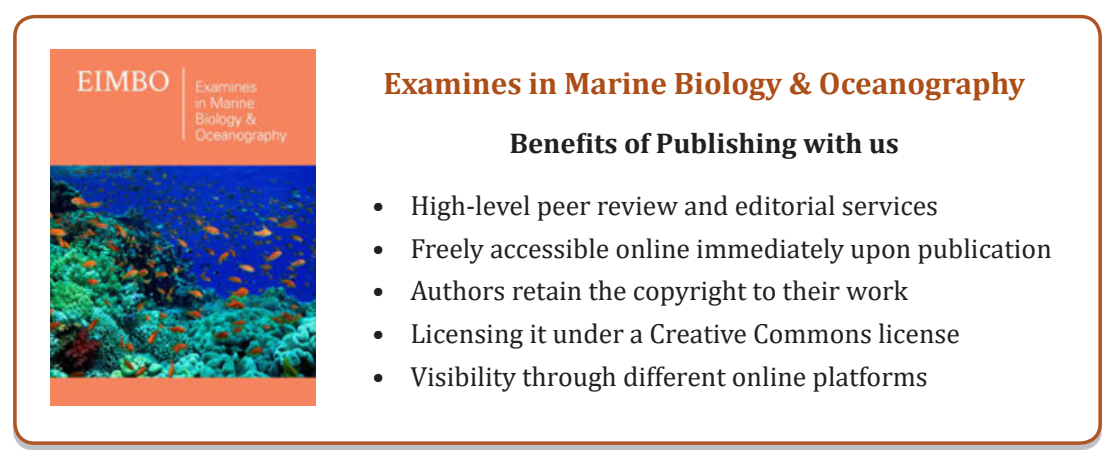

